\title{
DINÂMICA DA ATIVIDADE MICROBIANA DO SOLO SOB DIFERENTES AGROSSISTEMAS NO CERRADO BAIANO
}

Vitória Oliveira Andrade ${ }^{1}$; Inglid Lais Batista Cunha de Souza ${ }^{2}$; Gabriel Amorim Luduvico³; Thais dos Santos Rodrigues ${ }^{4}$; Msc. Cristiane Nair Fabrício Nunes ${ }^{5}$

DOI: $\underline{\text { https://doi.org/10.31692/978-65-991061-4-9.133-138 }}$

\section{INTRODUÇÃO}

A ocorrência da perturbação causada pela ação humana em sistemas estáveis (solo + cobertura vegetal), tende a acarretar perdas maiores do que ganhos de carbono, ocasionando assim, a redução da qualidade do solo ao longo do tempo. Com isso, pode-se relacionar essas perdas com a liberação de carbono na forma de $\mathrm{CO}_{2}$ do sistema solo para a atmosfera, através do processo de respiração, provenientes da decomposição da matéria orgânica do solo por hidrólise microbiana (ARAÚJO,2009).

Neste sentido, de forma complementar, a respiração edáfica pode ser definida como a produção de $\mathrm{CO}_{2}$, ou consumo de $\mathrm{O}_{2}$, como decorrência de processos metabólicos de organismos vivos no solo e abrange dois processos gerais: redução de C pelo sistema solo e reciclagem de nutrientes (SILVA, 2010). Desta forma, a respiração edáfica pode ser utilizada para registrar mudanças na dinâmica do carbono do solo em áreas que sofreram desmatamento para implantação de culturas (SOUTO et al.,2009).

Segundo Grisi (1976) os componentes bióticos do ecossistema são responsáveis por grande parte da respiração total do solo e que, quando em condições favoráveis de temperatura e umidade, seus valores tendem a se elevar, podendo ser possível que tais condições não sejam favoráveis durante o dia. Ou ainda, as condições ecológicas características de solo e clima da região levariam os microrganismos a tal comportamento. Dessa maneira, faz-se necessário esclarecer melhor essa particularidade relacionada à elevação e diminuição da atividade microbiana no solo.

Portanto, o presente trabalho tem como objetivo avaliar o comportamento da atividade microbiana diurna em três tipos de agrossistemas: Mandioca, Pinhão Manso e Mata nativa em decorrência da variação climática associada a esses diferentes tipos de uso do solo.

\footnotetext{
1 Graduando em Engenharia Agronômica, Universidade do Estado da Bahia- UNEB, Campus IX, vitoriasaogabriel2@gmail.com

2 Graduando Engenharia Agronômica, Universidade do Estado da Bahia, - UNEB, Campus IX, inglidlaiscunha@gmail.com

3 Graduando em Engenharia Agronômica, Universidade do Estado da Bahia- UNEB, Campus IX, luduvicoga@gmail.com

4 Graduando em Engenharia Agronômica, Universidade do Estado da Bahia - UNEB, Campus IX, thaissan98@gmail.com

${ }^{5}$ Mestrado em Ciências Ambientais, Universidade Federal da Bahia - UFBA, crisfabricio@ hotmail.com
}

[133] 


\section{Matéria Orgânica do Solo (MOS)}

A qualidade e a quantidade da matéria orgânica no solo é um fator determinante para os atributos edáficos, já que a mesma influência nas propriedades físicas, químicas e biológicas de solo. A matéria orgânica adicionada ao solo tem a planta como componente ativo no seu principal processo, desse modo, o estoque de MOS é consequência dos processos de perda e adição de material orgânico (ALMEIDA \& SANCHES, 2014).

A "respiração microbiana do solo" ou emissão de $\mathrm{CO}_{2}$ está intimamente relacionada a qualidade e ao teor de MOS e, como consequência, a própria diversidade biológica estará refletindo, a qualidade da matéria orgânica do solo (MAIA \& PARRON, 2015). O solo em suas condições naturais possui um conteúdo de carbono orgânico estabilizado, que representa as condições ambientais estabelecidas pelo clima, vegetação, topografia e por características do próprio solo. No entanto, as formas de uso e manejo do solo também são relevantes, particularmente, quando os ecossistemas nativos são transformados em áreas agrícolas (BALIM et al.,2017).

\section{Emissão de $\mathrm{CO}_{2}$ e Agrossistemas}

A contribuição do dióxido de carbono atmosférico para o aquecimento global tem aumentado o interesse pelo carbono orgânico do solo, por ser um dos principais compartimentos do ciclo terrestre deste elemento (BALDOTTO et al.,2015). A entrada e saída de carbono, em sistemas agrícolas, é influenciada pelo preparo do solo, espécies utilizadas, rotações de cultura, adubação e, principalmente, pelo manejo dos resíduos das culturas (COSER et al., 2016).

\section{METODOLOGIA}

O experimento foi executado no mês de agosto de 2019, na área experimental da Universidade do Estado da Bahia- Campus IX, município de Barreiras- BA, cujas coordenadas geográficas ( $44^{\circ} 59^{\prime} 33^{\prime}$ W W e $12^{\circ} 8$ ' 54” S), com altitude de $454 \mathrm{~m}$. O clima predominante na região é o Clima tropical com estação seca, baseado na Classificação climática Köeppen- Geiger: Aw. O solo, sendo classificado como LATOSSOLO VERMELHO-AMARELO Distrófico típico e o bioma Cerrado. A pesquisa tem como natureza, quantitativa do tipo experimental exploratória.

A quantificação do $\mathrm{CO}_{2}$ foi realizada de acordo com a metodologia de Grisi (1978), durante 12 horas (6:00 - 18:00) de hora em hora, e consiste na absorção do $\mathrm{CO}_{2}$ liberado do solo, pela solução de KOH 0,5 N. Para as análises, foram colocados $10 \mathrm{ml}$ da solução alcalina em potes de $500 \mathrm{ml}$, em triplicata, estas foram colocadas em um sistema campânula, contendo 
um balde de capacidade de 29 L juntamente com o frasco controle hermeticamente fechado. Após uma hora, foram titulados com $\mathrm{HCl} 0,1 \mathrm{~N}$ utilizando dois indicadores, a fenolftaleína à $1 \%$ e alaranjado de metila a $1 \%$ para a primeira e segunda viragem respectivamente. A massa de $\mathrm{CO}_{2}$ desprendido por unidade da área e tempo $\left(\mathrm{mg} \mathrm{m}^{-2} \mathrm{~h}^{-1}\right)$ foi calculada segundo a fórmula de Valentini (2015), como visto na equação 1.

$$
\mathrm{CO}_{2}\left(\mathrm{mg} \mathrm{m} \mathrm{m}^{-2} h^{-1}\right)=\frac{(\mathrm{VA}-\mathrm{VB}) \mathrm{NHCL} \times \mathrm{Eq} \mathrm{CO}_{2}}{A \times T} \times 10^{4} \times 4 / 3
$$

Equação 1

Em que VB representa a $\neq$ do volume do ácido clorídrico gasto na titulação do branco com os dois indicadores. VA $\neq$ dos volumes do ácido clorídrico gasto na titulação da amostra com os dois indicadores; $\mathrm{NHCl}$ é a normalidade do ácido clorídrico $(0,1 \mathrm{~N})$; Eq $\mathrm{CO}_{2}$ é a equivalente grama de CO2 (22); A é a área da campânula; T é o tempo de coleta em horas. 4/3 é o fator que corrige o valor do efluxo de $\mathrm{CO}_{2}$ no solo que pelo método químico é subestimado em $25 \%$.

Para o estudo da influência de temperatura e umidade sob a atividade microbiana nos solos, foram coletados dados climáticos no site oficial do Instituto Nacional de Meteorologia (IMNET).

\section{RESULTADOS E DISCUSSÃO}

Na medição da atividade microbiana, por um período de 12 horas em cada um dos agrossistemas (figura 1), nota-se que os valores mais elevados na mandioca, pinhão manso e mata nativa foram observados às 10 horas, 6 horas e 17 horas, respectivamente.

Figura 1: Variação diurna da respiração edáfica do solo nos diferentes agrossistemas estudados.

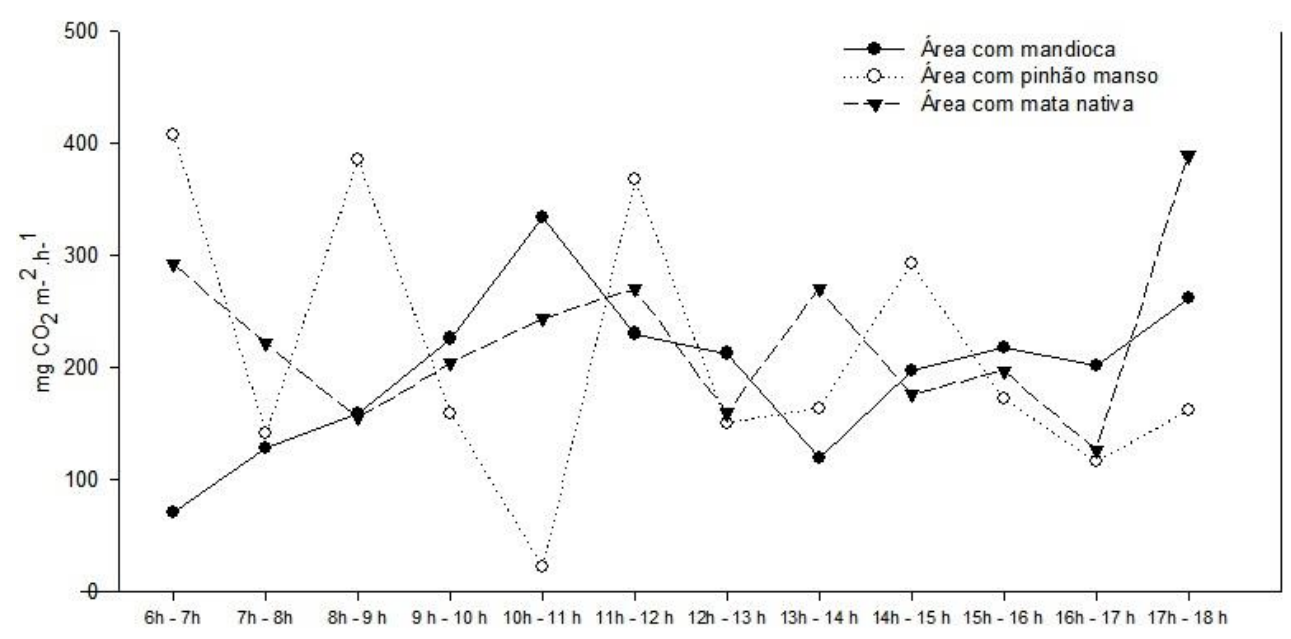

Fonte: Própria (2019) 
A mandioca (Manihot esculenta Crantz) é considerada a cultura com a mais alta produtividade de calorias e de maior eficiência biológica. Devido à necessidade de capinas e movimento do solo durante os estádios de desenvolvimento, pode deixar o solo descoberto e desprotegido, ocasionando a passagem de muita radiação solar (FERREIRA et al., 2015). Neste sentido, é importante ressair que a temperatura corresponde à um dos fatores que tende a influenciar na biótica do solo, alterando tanto a sua população, quanto as suas atividades.

Com isso, ao comparar a área da mandioca com a mata nativa (Stricto sensu), no primeiro horário (6-7 horas), observou-se que a mandioca apresentou uma taxa de respiração $75,75 \%$ menor do que a mata nativa. A umidade e temperatura média do ar nesse horário eram iguais a 44 a $46 \%$ e 24,7 a $22,9{ }^{\circ} \mathrm{C}$ respectivamente.

Do contrário, no período de 10 a 11 horas o solo cultivado com mandioca apresentou uma taxa respiratória de 37,28\% superior a mata nativa, com umidade de 53 a $51 \%$ e temperatura ambiente máxima de 20,9 a $21,9^{\circ} \mathrm{C}$. Ao final da tarde, das $16-17 \mathrm{~h}$, a taxa respiratória na área com mandioca se elevou em $60 \%$ de emissão de $\mathrm{CO}_{2}$ relacionada com a mata nativa. Essa elevação de emissão de $\mathrm{C}$ se dá por meio da temperatura que pode ser expressada devido ao ponto ótimo que os microrganismos estão ativos, assim, a partir deste ponto os mesmos podem desnaturar e com isso, diminuir sua atividade.

Em relação ao Pinhão Manso, o mesmo apresenta semelhança com os sistemas naturais, podendo representar uma combinação ideal no favorecimento da biota do solo, disponibilizando matéria orgânica e refúgio aos microrganismos, já que não há interferência do manejo intensivo (AGOSTINHO, 2017). Segundo Chagas (2008), o mesmo possui uma alta eficiência para a estocagem de carbono no solo. Porém, por estar consorciado com o Nim indiano que possui um princípio ativo chamado Azadiractina, extraído da sua parte aérea e tendo capacidade antimicrobiana e inseticida, o pinhão manso pode apresentar uma diminuição acentuada na atividade microbiana.

Neste sentido, quando confrontado a Pinhão Manso com a área de Mata nativa consorciado ao Nim indiano, os valores correspondentes as taxas de emissão de $\mathrm{CO}_{2}$ na área de Pinhão Manso que foram mais elevadas são: das 6-7 h; 8-9 h; 11-12 h e 14-15h; com os seguintes valores: 39,39\%; 148,32\%; 36,06\% e 65,70\% respectivamente . Dessa forma, notase que a área da mata nativa se manteve estabilizada em relação ao seu conteúdo de carbono orgânico, cujo a sua constância associa-se às condições ambientais do próprio solo, já que o mesmo não sofreu nenhum tipo de perturbação antrópica. 


\section{CONSIDERAÇÕES FINAIS}

Portanto, analisando as medições de hora em hora por um período de 12 horas, os diferentes tipos de sistemas de manejo trazem consigo diferentes condições ambientais, preparo do solo, manejo de resíduos, espécies utilizadas, dentre outros aspectos que favorecem a biota edáfica do solo, a qual irá influenciar na liberação de $\mathrm{C}$ na forma de $\mathrm{CO}_{2}$ do solo para a atmosfera pelo processo de respiração.

\section{REFRÊNCIAS}

AGOSTINHO, P. R. Indicadores biológicos de qualidade de solo em sistemas agroflorestais biodiversos para fins de recuperação de áreas degradadas. Embrapa Agropecuária OesteTese/dissertação (ALICE), 2017.

ALMEIDA, R. F.; SANCHES, B. C. Disponibilidade de carbono orgânico dos solos no cerrado brasileiro. Scientia Agraria Paranaensis, Marechal Candido Rondon, v.13, n. 4, p. 259-264, 2014.

ARAÙJO, Kallianna Dantas et al. Liberação de dióxido de carbono $\left(\mathrm{CO}_{2}\right)$ em área de caatinga no semiárido no Paraíba. Geoambiente Online, n. 12, p. 01-12 pág., 2009.

BALDOTTO, M. A. et al. Estoque e frações de carbono orgânico e fertilidade de solo sob floresta, agricultura e pecuária. Rev. Ceres, Viçosa, v.62, n. 3, p.301-309, 2015.

BALIN, N. M. et al. frações da matéria orgânica, índice de manejo do carbono e atributos físicos de um Latossolo vermelho sob diferentes sistemas de uso. Rev. Scientia Agraria, Curitiba, PR, v.18, n.3, p. 85-94, 2017.

CHAGAS, P. D. Esperança Nacional. Revista do Biodiselbr, Curitiba, v. 1, p. 24-34, 2008.

COSER, T. R. et al. Propriedades microbiológicas do solo e disponibilidade de nitrogênio para milho em monocultura e em consórcio com forrageiras. Pesq. Agropecuária. bras. Brasília, v.51, n.9, p.1660-1667,2016.

DA SILVA, Ruy Borges; DOS SANTOS, Antonio Clementino; BATISTA, Ruy Bezerra. Respiração Edáfica como indicativo na qualidade do solo em três Agrossistemas. 2010.

FERREIRA, Evander Alves et al. Atividade microbiana de solos cultivados com mandioca em sistema de policultivo. MAGISTRA, v.27, n.3/4, p.395-400, 2017.

GRISI, Breno Machado. Biodinâmica de solo cultivado com cacaueiros sombreados e ao sol. Rev. theobr, v. 6, p. 87-99, 1976.

GRISI, B. M. Metodo quimico de medicao da respiracao edafica; alguns aspectos tecnicos. Ciência e Cultura, 1978.

MAIA, C. M. B. F; PARRON, L. M. Matéria orgânica como indicador da qualidade do solo e 
da prestação de serviços ambientais. EMBRAPA, DF, 2015.

MARTINS, Lima Deleon et al. Efeito do corretivo escória de siderurgia e diferentes adubações no teor nutricional de folha de mamona e pinhão-manso. Revista Verde de Agroecologia e Desenvolvimento Sustentável, p. 135-145, 2009.

SANTOS, Adriana Avelino. Implantação do pinhão-manso em solo degradado inoculado e acrescido de macrófita, cinza e hidrogel. Ilha Solteira: UNESP, f.75, 2013.

SOUTO, Patrícia Carneiro et al. CINÉTICA DA RESPIRAÇÃO EDÁFICA EM DOIS AMBIENTES DISTINTOS NO SEMI-ÁRIDO DA PARAIBA, BRASIL. Revista Caatinga, v. 22, n.3, p. 52-58, 2009.

VALENTINI, Carla Maria Abido; DE ABREU, Joadil Gonçalves; DE FARIA, Rozilaine Aparecida Pelegrine Gomes. Respiração do solo como bioindicador em áreas degradadas. Revista Internacional de Ciências, v. 5, n. 2, p. 127-142, 2015. 